\title{
Lack of Association between Fingernail Selenium and Thyroid Cancer Risk: A Case-Control Study in French Polynesia
}

\author{
Yan Ren ${ }^{1,2,3}$, Cari Meinhold Kitahara ${ }^{4}$, Amy Berrington de Gonzalez ${ }^{4}$, Enora \\ Clero $^{1,2,3}$, Pauline Brindel ${ }^{1,2,3}$, Stephane Maillard ${ }^{1,2,3}$, Suzanne Cote ${ }^{5}$, Eric \\ Dewailly $^{5}$, Frederique Rachedi ${ }^{6}$, Jean-Louis Boissin ${ }^{7}$, Joseph Sebbag ${ }^{8}$, Larrys \\ Shan $^{9}$, Frederique Bost-Bezeaud ${ }^{6}$, Patrick Petitdidier ${ }^{10}$, Constance Xhaard ${ }^{1,2,3}$, \\ Carole Rubino ${ }^{1,2,3}$, Florent de Vathaire ${ }^{1,2,3 *}$
}

\begin{abstract}
Background: Numerous studies have suggested that selenium deficiency may be associated with an increased risk for several types of cancer, but few have focused on thyroid cancer. Materials and Methods: We examined the association between post-diagnostic fingernail selenium levels and differentiated thyroid cancer risk in a French Polynesian matched case-control study. Conditional logistic regression models were used to estimate odds ratios and $95 \%$ confidence intervals. Results: The median selenium concentration among controls was $0.76 \mathrm{\mu g} / \mathrm{g}$. Significantly, we found no association between fingernail selenium levels and thyroid cancer risk after conditioning on year of birth and sex and additionally adjusting for date of birth (highest versus lowest quartile: odds-ratio $=1.12,95 \%$ confidence interval: $0.66-1.90 ; p$-trend=0.30). After additional adjustment for other covariates, this association remained non-significant $(p$-trend $=0.60)$. When restricting the analysis to thyroid cancer of $10 \mathrm{~mm}$ or more, selenium in nails was non-significantly positively linked to thyroid cancer risk ( $p$-trend=0.09). Although no significant interaction was evidenced between iodine in nails and selenium in nails effect $(p=0.70)$, a non-significant $(p$-trend $=0.10$ ) positive association between selenium and thyroid cancer risk was seen in patients with less than 3 ppm of iodine in nails. The highest fingernail selenium concentration in French Polynesia was in the Marquises Islands $(M=0.87 \mu \mathrm{g} / \mathrm{g})$ and in the Tuamotu-Gambier Archipelago $(M=0.86 \mu \mathrm{g} / \mathrm{g})$. Conclusions: Our results do not support, among individuals with sufficient levels of selenium, that greater long-term exposure to selenium may reduce thyroid cancer risk. Because these findings are based on post-diagnostic measures, studies with prediagnostic selenium are needed for corroboration.
\end{abstract}

Keywords: Thyroid cancer - selenium - diet - fingernail - case-control study

Asian Pac J Cancer Prev, 15 (13), 5187-5194

\section{Introduction}

Thyroid cancer, the most common malignancy of the endocrine system, accounts for less than $2 \%$ of all cancers diagnosed worldwide (Ron and Schneider, 2006). Iodine and selenium are dietary factors for which there is the most information to play a role in the risk of differentiated thyroid cancer. Moreover, these elements and the family of molecules in which they are present (thyroid hormones, isothiocyanates, selenoproteines) are substrates of enzymes encoded by genes whose polymorphisms are most suspected to play a role in the risk of thyroid cancer: FOXE1, FOXE2 for iodine (Gudmundsson et al., 2009), and genetic family of Glutathione-S-transferases for selenium (Adjadj et al., 2009).

Selenium is an essential trace element present mainly in grains, meat, fish, eggs, and dairy products, as well as multivitamin supplements (Aaseth et al., 1990; Jung and Seo, 2010). Like iodine, the selenium content of a given food strongly depends upon the geographic location where it is produced, as plant uptake is largely influenced by the availability and chemical species of selenium in the soil (Aaseth et al., 1990). The redox-protective properties of selenium are important during oxidative thyroid hormone production, in which thyroid cells produce excess $\mathrm{H}_{2} \mathrm{O}_{2}$ and reactive oxygen species. Due to its ability to

${ }^{1}$ Radiation Epidemiology Group, Centre for Research in Epidemiology and Population Health (CESP), UMR 1018 Inserm, ${ }^{2}$ Gustave Roussy Institute, Villejuif, ${ }^{3}$ Faculty of Medicine, University Paris Sud 11, Le Kremlin-Bicêtre, France, ${ }^{4}$ Division of Cancer Epidemiology and Genetics, National Cancer Institute, National Institutes of Health, Rockville, USA, ${ }^{5}$ Area of population health and optimal health practices, CHU de Québec Research Center, Québec, Canada, ${ }^{6}$ Territorial Hospital Mamao, ${ }^{7} I P R A M E$, ${ }^{8}$ Paofai Clinic, ${ }^{9}$ Endocrinologist, ${ }^{10}$ Laboratoire Boz, Papeete, French Polynesia ${ }^{\circledR}$ Equal contributors ${ }^{*}$ For correspondence: Florent. DEVATHAIRE@gustaveroussy.fr 
protect the thyroid gland and maintain thyroid hormone production, there is a high concentration of selenium in the thyroid (Aaseth et al., 1990), and supply of selenium to the thyroid is prioritized even during periods of selenium deficiency (Fairweather-Tait et al., 2011).

Although numerous studies have shown that selenium deficiency may be associated with an increased risk for several types of cancer (Willett et al., 1983; Clark et al., 1996; Duffield-Lillico et al., 2002; Guo et al., 2012), the relationship between selenium and thyroid cancer has been examined in few studies. One in vitro study showed that selenium causes growth inhibition of thyroid cancer cells accompanied by cell-cycle arrest in the S and G2/M phases (Kato et al., 2010). In addition, a small case-control study of 43 thyroid cancer cases showed a significant increased risk for low compared to high prediagnostic serum selenium concentrations (Glattre et al., 1989).

In the present study, we examined the association between fingernail selenium concentrations with thyroid cancer in a case-control study of men and women in French Polynesia, a country who has high incidence of thyroid cancer in females (Moore et al., 2010) also highly exposed to selenium mainly through fish consumption (Dewailly et al., 2008). In contrast to other biomarker measures of selenium, such as blood or urine, nail concentrations represent longer-term exposure, typically the previous three to six months. This case-control study has already shown that a high number of pregnancies (Brindel et al., 2008), tallness and obesity (Brindel et al., 2009; Clero et al., 2010), familial history of thyroid cancer (Brindel et al., 2010), low dietary intake of iodine (Clero et al., 2012), poor economic conditions (De Vathaire et al., 2010), and nuclear radiation fallout (De Vathaire et al., 2010), having a spring as the main source of drinking water (Xhaard et al., 2014) are thyroid cancer risk factors in French Polynesia.

\section{Materials and Methods}

\section{Selection of cases and controls}

The process for selection and interviews of thyroid cancers and controls has been extensively described elsewhere (De Vathaire et al., 2010). Eligible cases were born and resided in French Polynesia and had been diagnosed with differentiated thyroid cancer before the age of 56 between 1981 and 2003. Four patients between the ages of 56 and 62 at diagnosis, one case diagnosed in 1979, and two cases diagnosed in 2004 were included in the study inadvertently and were retained in the analysis. The cases were identified from the cancer registry in French Polynesia, medical insurance files, and/or four endocrinologists in Tahiti. Information on histology was obtained from the two histopathology laboratories in Tahiti and/or the endocrinologists' medical files. Of the 255 eligible differentiated thyroid cancer cases, 26 (10\%) were not interviewed because they had died $(n=14)$, could not be located $(n=6)$, refused to participate $(n=5)$, or were too ill to participate in the interview $(n=1)$.

For each case, two controls were randomly selected from the birth registry in French Polynesia and matched to each case by date of birth $( \pm 3$ months for the first interviewed controls, increased by \pm 20 days afterwards) and sex. Of the 458 randomly selected controls, 85 (19\%) were not interviewed for the study because they had died $(n=9)$, could not be located $(n=29)$, refused to participate $(n=29)$, were too ill to participate in the interview $(n=2)$, or they no longer resided in French Polynesia $(n=16)$. After these exclusions, 35 cases had one and 25 cases had no matched controls. Each of the 25 cases with no matched control was then matched to a control from among cases that had two matched controls; the matching criteria for date of birth were relaxed if necessary.

In total, the study population included 229 interviewed cases and 373 interviewed controls, with 85 cases (37\%) matched to one control and 144 cases $(63 \%)$ matched to two controls. We further excluded 6 cases and 9 controls for missing data on fingernail selenium, and a batch of 8 cases and 33 controls for which all measures of any elements in the fingernails were returned as null. The final analytic population was 215 cases and 331 controls.

The French Polynesian Ethics Committee approved the study, and written informed consent to participate in the study and to contact his or her physician was obtained from each participant.

Detailed characteristics of cases and controls are, as well as thyroid cancer risk factor estimates are reported elsewhere (de Vathaire et al. 2010, Xhaard et al., 2014).

\section{Data collection}

Home addresses for cases and controls were obtained through the territorial medical insurance plan that offers coverage for all inhabitants. In-person interviews were conducted in the participants' homes (though some cases were interviewed at the hospital on the day of their usual follow-up consultation) by trained interviewers and medical staff using a structured questionnaire which included questions regarding ethnicity, education, smoking, weight at various ages, personal history of thyroid disease and cancer, places of residence, reproductive and hormonal exposures, history of medical $\mathrm{X}$-rays and diet.

We used a French food composition table (Favier et al., 1995) for the calculation of iodine and selenium intake because data were lacking in the Pacific Islands food composition tables (Dignan et al., 2004). The overall iodine intake took into account all foods of the questionnaire, except iodized salt because we had no information on the amount of iodized salt consumption.

All participants provided fingernail clippings on the date of the interview. Clippings were stored in paper envelopes at room temperature before being transferred to the toxicology centre of the Institut National de Sante Publique du Quebec (INSPQ).

\section{Fingernail selenium and iodine measurements}

Nail samples were digested under basic conditions using trimethylammonium hydroxide for iodine and under acidic conditions with nitric acid for selenium. The digested material was directly analysed by ICP-MS (inductively coupled plasma mass spectrometry, Perkin Elmer Sciex, Elan DRCII with autosampler ESI SC-4 and work station Elan version 3.0) (Elwaer and Hintelmann, 
2007). Certified reference materials used were: Human hair powder GBW 07601 and GBW 09101b.

\section{Statistical analysis}

Descriptive statistics and trend tests in univariate analysis were performed using non-parametric JonckheereTerpstra test for association between two quantitative variables; non-parametric Wilcoxon rank test for association between a qualitative variable with two classes and a quantitative variable; and non-parametric KruskalWallis rank tests for association between a qualitative variable with more than two classes and a quantitative variable.

The association between selenium in nails and other parameters has been investigated using generalized linear models.

We used conditional logistic regression to estimate OR and 95\%CI for thyroid cancer by fingernail selenium concentration. Selenium was categorized into quartiles based on the distribution among the controls. All models were conditioned on year of birth $(<1945,1945-1955$, $1955-1965, \geq 1965)$ and sex to reduce the potential bias due to the matching process and adjusted for year of birth (continuous, per year) to control for residual confounding by age. Multivariable models were additionally adjusted for ethnicity (Polynesian, mixed, other), education (primary school or lower vs. middle school or higher), BMI at the moment of cancer $\left(<25,25-29.9, \geq 30 \mathrm{~kg} / \mathrm{m}^{2}\right.$, missing), current smoking (yes vs. no), and radiotherapy treatment to head or neck (ever vs. never). These associations were also evaluated by sex, smoking status,
BMI, thyroid cancer histology, tumour size, fingernail iodine and dietary iodine. Effect modification of selenium levels by sex, smoking status, BMI, thyroid cancer histology, tumour size, fingernail iodine and dietary iodine was evaluated using the likelihood ratio test comparing a model with an interaction term to one without. We also investigated for potential bias due to the delay between thyroid cancer diagnosis and fingernails sampling, by performing separate analysis for various categories of delay.

All statistical analyses were conducted using SAS software (version 9.3, SAS Institute Inc., Cary, NC, USA).

\section{Results}

The cases and controls were generally comparable in terms of ethnicity and level of education. Thirty percent of the tumours were less than $10 \mathrm{~mm}$. About $70 \%$ of cases had papillary thyroid cancer, and $30 \%$ had a follicular type.

Among controls, higher fingernail selenium levels were observed in older people $(\mathrm{p}<0.001)$, and people who have higher BMI $(\mathrm{p}=0.001)$ and in non-smokers $(\mathrm{p}<0.0001)$, but in a multivariate analysis, only age $(\mathrm{p}=0.01)$ and smoking $(\mathrm{p}<0.0001)$ remained significant (Table 1). The highest fingernail selenium levels were in inhabitants of the Marquises Islands $(\mathrm{M}=0.87 \mu \mathrm{g} / \mathrm{g})$ and of the Tuamotu-Gambier Archipelago $(\mathrm{M}=0.86 \mu \mathrm{g} / \mathrm{g})$ (Figure 1). Adjusting by other factors, including estimated selenium and iodine in diet, selenium in the fingernails of controls from the Tuamotu-Gambier Archipelago remained significantly higher than in the rest of French

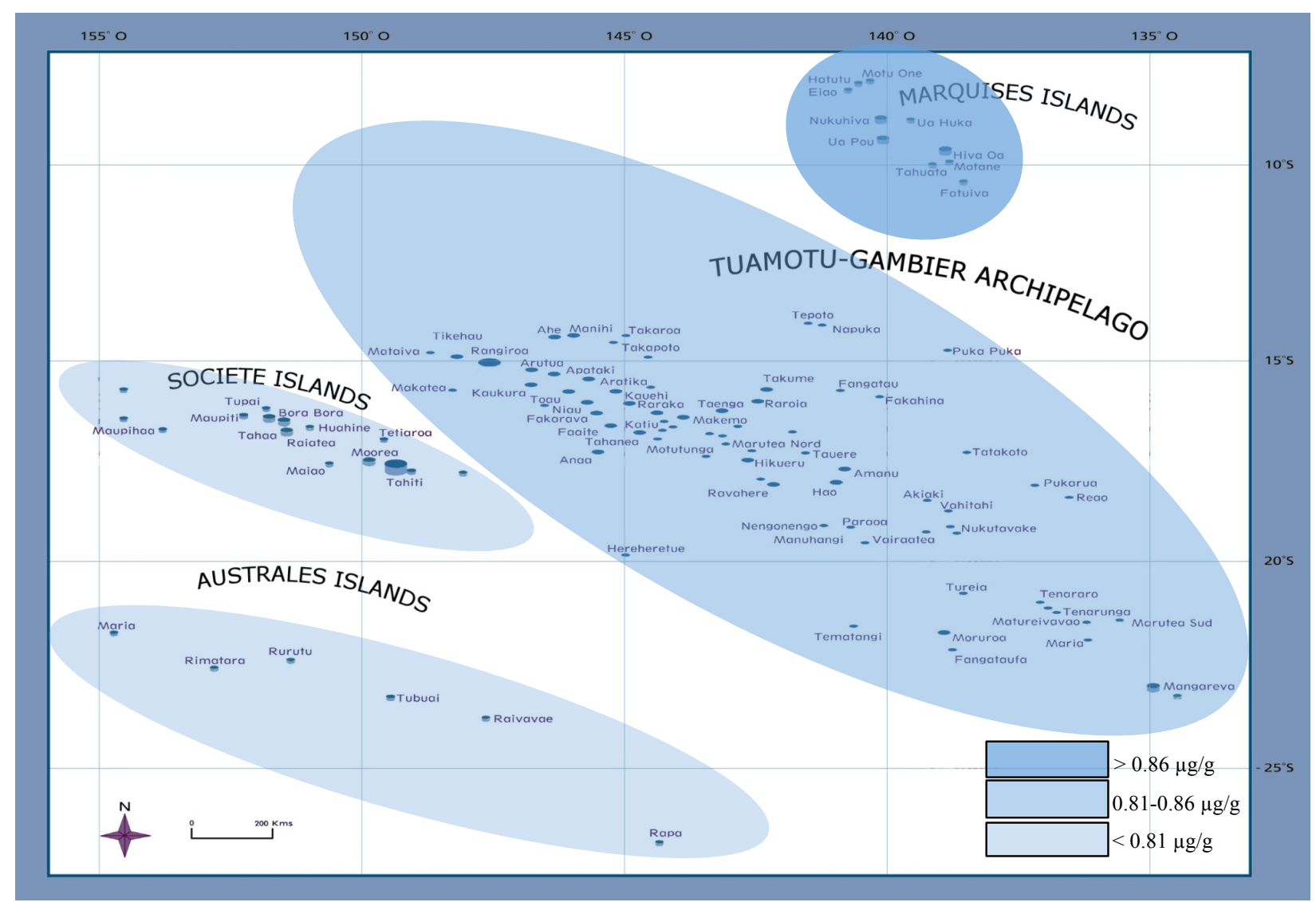

Figure 1. Fingernail Selenium Concentration in Studied Population of French Polynesia 
Polynesian, but not from the Marquises Islands (Table 1). On the contrary, among cases, only selenium in fingernails of the Marquises Islands inhabitants remained higher than in the other inhabitants of French Polynesia $(p=0.05)$ (Table 1).

We did not evidence a significant association between fingernail selenium levels and thyroid cancer risk in models that were conditioned on year of birth and gender and further adjusted for year of birth (highest versus lowest quartile: $\mathrm{OR}=1.12,95 \% \mathrm{CI}: 0.66-1.90 ; \mathrm{p}$-trend $=0.30$ ) (Table 2). After additional adjustment for age at the moment of the diagnosis of cancer, ethnicity, education, BMI, smoking status and radiotherapy treatment to the head or neck, this association with the risk of thyroid cancer comparing the highest to the lowest quartile was also non-significant $(\mathrm{OR}=1.02,95 \% \mathrm{CI}$ : 0.56-1.84; p-trend $=0.60)$ (Table 2).

Among the studied population, average fingernail selenium concentration was $0.75 \mu \mathrm{g} / \mathrm{g}$ in smokers and $0.80 \mu \mathrm{g} / \mathrm{g}$ in non-smokers $(\mathrm{p}<0.0001)$. We did not observe evidence for a significant effect modification by sex, smoking status, BMI, histological type, fingernail iodine and dietary iodine (all p-interaction $>0.05$; Table 2). A significant interaction was evidenced between selenium and tumour size $(\mathrm{p}=0.04)$ : when restricting the analysis to differentiated thyroid cancer of $10 \mathrm{~mm}$ or more, selenium in nails was nearly significantly positively $(p=0.09)$ linked to thyroid cancer risk. Although no significant interaction

Table 1. Predictor of Selenium Concentration in Fingernails in Thyroid Cancer Patients and Controls

\begin{tabular}{|c|c|c|c|c|}
\hline & \multicolumn{2}{|c|}{ Cases } & \multicolumn{2}{|c|}{ Controls } \\
\hline & Regression Coefficient (SD $\dagger)$ & p-value* & Regression Coefficient (SD $†$ ) & p-value* \\
\hline Dietary selenium (mg/1,000 kcal) & $<0.001(<0.001)$ & 0.60 & $-0.0002(<0.001)$ & 0.06 \\
\hline Dietary iodine $(\mathrm{mg} / 1,000 \mathrm{kcal})$ & $-0.0002(<0.001)$ & 0.30 & $0.0001(<0.001)$ & 0.20 \\
\hline Gender (women/men) & $-0.01(0.03)$ & 0.80 & $0.04(0.02)$ & 0.06 \\
\hline Age (years) & $0.001(0.001)$ & 0.20 & $0.002(<0.001)$ & 0.01 \\
\hline BMI $\left(\mathrm{kg} / \mathrm{m}^{2}\right)$ & $0.003(0.002)$ & 0.03 & $0.002(0.001)$ & 0.07 \\
\hline Currently smoking (yes/no) & $-0.05(0.02)$ & 0.01 & $-0.06(0.01)$ & 0.0001 \\
\hline Marquises Islands (yes/no) & $0.14(0.07)$ & 0.05 & $0.04(0.06)$ & 0.40 \\
\hline Tuamotu-Gambier Archipelago (yes/no) & $0.06(0.04)$ & 0.10 & $0.12(0.03)$ & 0.0002 \\
\hline
\end{tabular}

$\dagger$ Standard deviation; *Regression coefficient t-test

Table 2. Fingernail Selenium and Thyroid Cancer by Various Confounding Factors in French Polynesia, 1981-2003

\begin{tabular}{|c|c|c|c|c|c|c|c|}
\hline & & \multicolumn{6}{|c|}{ Quartiles of selenium $(\mu \mathrm{g} / \mathrm{g})$} \\
\hline & & $\begin{array}{c}\text { Q1 } \\
(0.00-0.68)\end{array}$ & $\begin{array}{c}\text { Q2 } \\
(0.68-0.76)\end{array}$ & $\begin{array}{c}\text { Q3 } \\
(0.76-0.86)\end{array}$ & $\begin{array}{c}\text { Q4 } \\
(0.86-1.30)\end{array}$ & p-trend* & p-interaction $* *$ \\
\hline \multirow[t]{3}{*}{ Overall } & Cases/controls & $51 / 93$ & $56 / 81$ & $50 / 79$ & $58 / 78$ & & \\
\hline & OR $(95 \% \mathrm{CI}) 1$ & 1.00 & $1.16(0.70-1.94)$ & $1.06(0.64-1.77)$ & $1.12(0.66-1.90)$ & 0.30 & \\
\hline & OR $(95 \%$ CI $) 2,3$ & 1.00 & $1.08(0.62-1.90)$ & $1.10(0.62-1.96)$ & $1.02(0.56-1.84)$ & 0.60 & \\
\hline \multirow[t]{2}{*}{ Men } & Cases/controls & $2 / 15$ & $8 / 9$ & $6 / 5$ & $7 / 11$ & & \\
\hline & OR $(95 \%$ CI $) 2,3$ & 1.00 & $? \dagger$ & $? \dagger$ & $752.6(<0.001->? \dagger)$ & 0.99 & \\
\hline \multirow[t]{2}{*}{ Women } & Cases/controls & $49 / 78$ & $48 / 72$ & $44 / 74$ & $51 / 67$ & & \\
\hline & OR $(95 \%$ CI $) 2,3$ & 1.00 & $0.95(0.53-1.71)$ & $0.95(0.51-1.74)$ & $0.90(0.48-1.70)$ & 0.90 & 0.20 \\
\hline \multirow[t]{2}{*}{ Non-smoker } & Cases/controls & $15 / 33$ & $20 / 40$ & $27 / 47$ & $32 / 49$ & & \\
\hline & OR $(95 \%$ CI $) 2,3$ & 1.00 & $0.91(0.38-2.18)$ & $1.02(0.45-2.32)$ & $1.07(0.47-2.46)$ & 0.50 & \\
\hline \multirow[t]{2}{*}{ Current smoker } & Cases/controls & $36 / 60$ & $36 / 41$ & $23 / 32$ & $26 / 29$ & & \\
\hline & OR $(95 \%$ CI $) 2,3$ & 1.00 & $1.29(0.68-2.43)$ & $1.08(0.53-2.19)$ & $1.19(0.59-2.41)$ & 0.40 & 0.70 \\
\hline \multirow[t]{2}{*}{$\mathrm{BMI}<30 \mathrm{~kg} / \mathrm{m}^{2}$} & Cases/controls & $35 / 68$ & $27 / 52$ & $23 / 53$ & $24 / 48$ & & \\
\hline & OR $(95 \%$ CI $) 2,3$ & 1.00 & $0.95(0.49-1.84)$ & $0.81(0.41-1.62)$ & $0.76(0.37-1.55)$ & 0.80 & \\
\hline \multirow[t]{2}{*}{$\mathrm{BMI} \geq 30 \mathrm{~kg} / \mathrm{m}^{2}$} & Cases/controls & $16 / 25$ & $28 / 28$ & $27 / 26$ & $34 / 30$ & & \\
\hline & OR $(95 \%$ CI $) 2,3$ & 1.00 & $1.65(0.70-3.90)$ & $1.74(0.73-4.18)$ & $1.97(0.83-4.66)$ & 0.15 & 0.30 \\
\hline \multirow[t]{2}{*}{ Papillary } & Cases/controls & $40 / 58$ & $39 / 56$ & $37 / 66$ & $49 / 56$ & & \\
\hline & OR $(95 \%$ CI $) 2,3$ & 1.00 & $0.95(0.52-1.76)$ & $0.81(0.44-1.49)$ & $1.18(0.64-2.18)$ & 0.30 & \\
\hline \multirow[t]{2}{*}{ Follicular } & Cases/controls & $11 / 25$ & $17 / 19$ & $13 / 10$ & $9 / 20$ & & \\
\hline & OR $(95 \%$ CI $) 2,3$ & 1.00 & $1.74(0.59-5.08)$ & $3.79(1.12-12.8)$ & $0.98(0.29-3.29)$ & 0.80 & 0.60 \\
\hline \multirow[t]{2}{*}{ Tumours $<10 \mathrm{~mm}$} & Cases/controls & $9 / 25$ & $15 / 20$ & $17 / 25$ & $18 / 24$ & & \\
\hline & OR $(95 \%$ CI $) 2,3$ & 1.00 & $1.84(0.59-5.75)$ & $1.79(0.61-5.29)$ & $1.84(0.59-5.75)$ & 0.30 & \\
\hline \multirow[t]{2}{*}{ Tumours $\geq 10 \mathrm{~mm}$} & Cases/controls & $32 / 59$ & $30 / 49$ & $28 / 43$ & $33 / 39$ & & \\
\hline & OR $(95 \%$ CI $) 2,3$ & 1.00 & $1.04(0.53-2.02)$ & $1.19(0.60-2.36)$ & $1.37(0.69-2.72)$ & 0.09 & 0.04 \\
\hline \multirow[t]{2}{*}{ Fingernail iodine $<3 \mathrm{ppm}$} & Cases/controls & $24 / 49$ & $23 / 43$ & $25 / 45$ & $27 / 39$ & & \\
\hline & OR $(95 \%$ CI $) 2,3$ & 1.00 & $0.98(0.46-2.09)$ & $1.18(0.56-2.49)$ & $1.44(0.66-3.11)$ & 0.10 & \\
\hline \multirow[t]{2}{*}{ Fingernail iodine $\geq 3 \mathrm{ppm}$} & Cases/controls & $27 / 44$ & $33 / 38$ & $25 / 34$ & $31 / 39$ & & \\
\hline & OR $(95 \%$ CI $) 2,3$ & 1.00 & $1.15(0.56-2.37)$ & $1.13(0.52-2.47)$ & $0.99(0.47-2.06)$ & 0.90 & 0.70 \\
\hline \multirow{4}{*}{$\begin{array}{l}\text { Dietary iodine }<117 \\
(\mathrm{mg} / 1,000 \mathrm{kcal}) \\
\text { Dietary iodine } \geq 117 \\
(\mathrm{mg} / 1,000 \mathrm{kcal})\end{array}$} & Cases/controls & $29 / 38$ & $29 / 49$ & $23 / 35$ & $35 / 36$ & & \\
\hline & OR $(95 \%$ CI $) 2,3$ & 1.00 & $0.83(0.41-1.70)$ & $0.95(0.44-2.06)$ & $1.40(0.67-2.95)$ & 0.10 & \\
\hline & Cases/controls & $22 / 55$ & $27 / 32$ & $27 / 44$ & $23 / 42$ & & \\
\hline & OR $(95 \%$ CI $) 2,3$ & 1.00 & $1.71(0.80-3.64)$ & $1.31(0.63-2.72)$ & $0.94(0.43-2.06)$ & 0.90 & 0.50 \\
\hline
\end{tabular}


Table 3. Fingernail Selenium and Thyroid Cancer by the Time between Diagnosis and Interview in French Polynesia, 1981-2003

\begin{tabular}{|c|c|c|c|c|}
\hline & \multicolumn{3}{|c|}{ Tertiles of selenium $(\mu \mathrm{g} / \mathrm{g})$} & \multirow[b]{2}{*}{ p-trend } \\
\hline & $\begin{array}{c}\mathrm{Q1} \\
0.00-0.71)\end{array}$ & $\begin{array}{c}\mathrm{Q} 2 \\
(0.71-0.82)\end{array}$ & $\begin{array}{c}\mathrm{Q3} \\
(0.82-1.30)\end{array}$ & \\
\hline \multicolumn{5}{|l|}{$<3$ years } \\
\hline Cases/controls & $17 / 34$ & $13 / 24$ & $16 / 23$ & \\
\hline OR $(95 \%$ CI $) 1$ & 1.00 & $1.03(0.38-2.80)$ & $1.24(0.48-3.23)$ & 0.20 \\
\hline \multicolumn{5}{|l|}{ 3-7 years } \\
\hline Cases/controls & $16 / 33$ & $18 / 24$ & $28 / 38$ & \\
\hline OR $(95 \%$ CI $) 1$ & 1.00 & $1.15(0.43-3.04)$ & $1.19(0.49-2.90)$ & 0.80 \\
\hline \multicolumn{5}{|l|}{$7-11$ years } \\
\hline Cases/controls & $21 / 37$ & $20 / 23$ & $18 / 31$ & \\
\hline OR $(95 \%$ CI $) 1$ & 1.00 & $1.82(0.72-4.60)$ & $1.03(0.41-2.61)$ & 0.50 \\
\hline \multicolumn{5}{|l|}{$\geq 11$ years } \\
\hline Cases/controls & $13 / 18$ & $17 / 27$ & $18 / 19$ & \\
\hline OR $(95 \%$ CI $) 1$ & 1.00 & $0.93(0.30-2.88)$ & $1.75(0.53-5.77)$ & 0.40 \\
\hline
\end{tabular}

was evidenced between iodine in nails and selenium in nails effect $(p=0.70)$, a nearly significant positive association $(\mathrm{p}=0.10)$ between selenium and thyroid cancer risk was seen in patients with less than $3 \mathrm{ppm}$ of iodine in nails. A similar result also has been found in which a nearly significant positive association $(p=0.10)$ between selenium and thyroid cancer risk was seen in patients with less than $117 \mathrm{mg} / 1,000 \mathrm{kcal}$ of dietary iodine (Table 2).

There was no clear association of fingernail selenium for cases who were interviewed and provided fingernail samples less than 3 years, 3 to 7,7 to 11 or more than 11 years after diagnosis (all p-trend $>0.05$; Table 3 ).

\section{Discussion}

Our objective was to examine the association between fingernail selenium concentrations and thyroid cancer in French Polynesia, a country highly exposed to selenium mainly through fish consumption and characterized by mild iodine deficiency (Clero et al., 2012).

Overall, we did not evidence a significant association between fingernail selenium levels and thyroid cancer risk. Fingernail selenium levels were higher in subjects with high BMI and in non-smokers, and among controls only, in older subjects. Furthermore, fingernail selenium levels were higher in inhabitants of the Marquises Islands and the Tuamotu-Gambier Archipelago. Selenium in nails was nearly significantly positively linked to the risk of thyroid cancer of $10 \mathrm{~mm}$ or more $(\mathrm{p}=0.09)$. Lastly, a nearly significant positive association $(p=0.10)$ between selenium and thyroid cancer risk was seen in patients with less than 3 ppm of iodine in nails.

This analysis has important strengths including, the population-based design with virtually exhaustive identification of thyroid cancer cases in isolated Pacific Islands and a high participation rate among cases and population control subjects, which were from the population register of French Polynesia (Brindel et al., 2009). Another important strength is that French Polynesia ranks as one of world's leading consumers of fish
(Dewailly et al., 2008), a major dietary source of selenium (Dewailly et al., 2008), which increased the power of our analysis. Furthermore, despite recent changes in lifestyle and nutrition, an important proportion of inhabitants (at least the ones living outside Tahiti), still have a traditional diet of fish, starchy roots and fruits, and consumed at the time of interview few imported foods that are high in fat and low in fibre (World Health Organization, 2003), and thus are more likely to accurately report their dietary intake.

This analysis also has some limitations. In regard to the statistical method, when we conditioned on age and sex using the original matching criteria (year of birth \pm 6 months and sex), we observed similar results but reduced statistical power since matched groups that were missing either a case or control were dropped from the analysis.

Because of the transition in diet habits from a traditional Polynesian diet to a more Westernized one, the results of this case-control study about diet in adulthood could be confounded by diet in previous periods.

We did not find a correlation between selenium measured in fingernails and dietary selenium intake, as estimated using dietary questionnaire data and a French food composition. This lack of correlation was not surprising because the concentration of selenium in foods is largely variable and its quantification from food composition table data is uncertain. Indeed, its concentration in vegetables is dependent on the soil content in a particular geographical location (Aaseth et al., 1990), and its concentration in fishes is dependent on the type of cooking and variable between species (Favier et al., 1995). Therefore, our estimation of selenium in diet is probably uncertain. Thus, biomarker measures are essential in investigating the relationship between selenium exposure and chronic disease risk.

Selenium concentration in nails is a highly reproducible value. In a cohort on the investigation of dietary supplement use and cancer risk in Western Washington state, the concentration of toenail selenium without selenium supplement was about six times higher than the concentration of plasma selenium without selenium supplement, mean toenail and plasma concentrations were $1.02 \pm 0.21 \mu \mathrm{g} / \mathrm{g}$ and $161 \pm 29 \mu \mathrm{g} / \mathrm{L}$, respectively (Satia et al., 2006). There are advantages to measure selenium concentration in fingernails rather than blood: the quantity of selenium in nails is more stable, cumulative, and integrates exposure occurring from 12 to 18 months before sampling (Fleckman, 1985). Additionally, collecting, transporting and storing fingernails are easier than blood.

A previous cross-sectional study, including 195 adults aged 18 years old and over from Tahiti and the Moorea islands, found that serum selenium levels in French Polynesia in 2008 were similar to those observed in Inuit adults in 1992; however, these are four times lower than France (foods imported to Polynesia come from France), even considering the whole blood/plasma ratio (Dewailly et al., 2008).

We found that the highest fingernail selenium concentrations of French Polynesia were in the Marquises Islands and in the Tuamotu-Gambier Archipelago, which is similar to observations performed on cord blood selenium 
concentration in French Polynesian new-borns in 2008 (Dewailly et al., 2008). These highest values are probably mostly attributable to higher seafood consumption, but the results shown in Table 1, in which the higher fingernail selenium values in controls living in the Tuamotu-Gambier Archipelago remains when adjusting for estimated dietary selenium intake, showing that other factors could interact, or that selenium level could be higher in the TuamotuGambier Archipelago fishes. Because most of the fishes eaten in the atolls of the Tuamotu-Gambier Archipelago come from the lagoon, rather than the open sea like other archipelagos of French Polynesia, this result could be due to an under-estimation of selenium contents for lagoon fishes in food composition tables.

Among the studied population, fingernail selenium concentration averages in French Polynesian, 0.75 ppm in smokers and $0.80 \mathrm{ppm}$ in non-smokers $(\mathrm{p}<0.0001)$, are very similar to those measured in other studies, and in particular in a large cohort study of US women, which have shown that toenail selenium was significantly reduced among cigarette smokers $(\mathrm{M}=0.75, \mathrm{SD}=0.12$, among 146 current smokers; and $\mathrm{M}=0.82, \mathrm{SD}=0.16$, among 311 never smokers; $\mathrm{p}<0.001$ ) (Hunter et al., 1990).

We found a positive relationship between BMI and selenium in fingernails, both in cases and controls (Table 1). Our result is in opposition with most European surveys(Arnaud et al., 2006; Meplan et al., 2007; Ortega et al., 2012) or US populations (Bleys et al., 2009), in which obese patients have lower serum selenium concentration, but in agreement with Dewailly's survey of a French Polynesian sampling in which selenium concentration in blood was positively linked to BMI (Dewailly et al., 2008), the regression coefficient $(\beta)$ being 0.02 , i.e. ten times higher than in our study, among the controls $(\beta=0.002)$. A possible explication is that in the general population, BMI has a trend to rise with age, if we do not consider extreme ages. Furthermore, older people have more possibilities to eat traditional food, which is rich in selenium.

There may be a range of selenium that offers optimal protection against cancer development in general, as a deficiency in selenium has been associated with an increased risk of cancer, this association having been evidenced for selenium in hair and nails and prostate cancer in Malaysia (Karimi et al., 2012), and selenium in serum and, respectively bladder carcinoma in China (Guo et al., 2012), and breast cancer in India (Singh et al., 2005). In the latter case-control study, it has been estimated that each increase of one $\mu \mathrm{mol} / \mathrm{l}$ of selenium was associated to decrease in $7 \%$ of breast cancer risk (Singh et al., 2005). Nevertheless, selenium supplementation may reduce cancer risk only in selenium-deficient individuals.

Few studies have examined the association between selenium and thyroid cancer risk, however, we haven't found association between fingernail selenium and thyroid cancer risk in our results. In a case-control study of 43 cases and 129 matched controls in Norway, prediagnostic serum selenium levels were inversely associated with thyroid cancer; levels $\leq 1.25$ and 1.26-1.64 $\mu \mathrm{mol} / 1$ were associated with a 7.70- and 6.10-fold increased risk of thyroid cancer compared to levels $\geq 1.65 \mu \mathrm{mol} / 1$ (Glattre et al., 1989). This case-control study also showed, when considering the delay from blood sampling to diagnosis of the case, that the protective effect of high serum selenium concentrations was restricted to the seven-year period prior to the diagnosis of thyroid cancer, because the serum selenium concentration of cases tended to decrease, relatively to controls, when the delay from blood sampling to the diagnosis was shorter. Similarly, in an Austrian survey the average selenium blood concentration was $1.14 \mu \mathrm{mol} / \mathrm{l}$ in 554 healthy controls, $0.97 \mu \mathrm{mol} / 1$ in 42 patients with follicular thyroid carcinoma and 1.02 $\mu \mathrm{mol} / 1$ in 73 patients with papillary thyroid carcinoma (Moncayo et al., 2008).

Our study did not evidence a significant association between fingernail selenium levels and thyroid cancer, even when considering only patients for which the delay between cancer diagnosis and nails sample was less than seven or less than three years (Table 3 ). It has to be noted that over a period of six years, selenium in toenails was one of the most reproducible trace elements (Garland et al., 1993). Therefore, our non-significant results are probably not due to the fact that we investigated post-diagnosis selenium levels rather than prediagnosis ones, except if thyroid cancer, by itself, modifies selenium level in nails. A possible explication for the lack of association could be the iodine status of French Polynesians, who could be less frequently iodine deficient than Norwegians because selenium acts synergistically with iodine. These results could nevertheless also be due to the fact that fingernail samplings among cases were performed after thyroid cancer diagnosis and therefore during thyroid hormone substitution treatment, such as levothyrox, which could interact with selenium. Indeed, all three mono-deiodinase enzymes are selenium-dependent and are involved in thyroid hormone regulation. In this way, selenium status may affect both thyroid hormone homeostasis and iodine availability (Cann et al., 2000; Brauer et al., 2006; Köhrle and Gärtner, 2009). Lastly, we evidenced a nearly significant positive association $(\mathrm{p}=0.15)$ between fingernail selenium and thyroid cancer risk in patients with more than $30 \mathrm{~kg} / \mathrm{m}^{2} \mathrm{BMI}$ (Table 2). This result has to be considered with caution because it is nearly significant, but it could be due to some specificity of obese patients.

Because cigarette smoking has been shown to be inversely associated with both selenium status(Lloyd et al., 1983) and thyroid cancer risk (Meinhold et al., 2010), it was important to adequately control for these exposures in our analysis. Despite having evidenced a lower selenium status in smokers than in non-smokers, we failed to show an interaction between fingernail selenium levels, smoking habit and thyroid cancer risk: both in smokers and nonsmokers, selenium status did not influence thyroid cancer risk. Nevertheless, it should be noted that such interaction tests are not very powerful in our study, given the number of patients.

In summary, our results do not support, among individuals with sufficient levels of selenium, that greater long-term exposure to selenium may reduce thyroid cancer risk. Because these findings are based on post-diagnostic measures, studies with prediagnostic selenium are needed for corroboration. 


\section{Acknowledgements}

This study was supported by the Association pour la Recherche contre le Cancer, the Ligue Nationale Contre le Cancer, the Direction Generale de la Sante, the Comite de radioprotection de Electricite de France, Agence Française de Securite Sanitaire et Environnementale et du Travail, CHILD-THYR EEC programme and the Fondation de France.

The first author Yan Ren has a scholarship from the Fondation de France for her Ph.D study.

\section{References}

Aaseth J, Frey H, Glattre E, et al (1990). Selenium concentrations in the human thyroid gland. Biol Trace Elem Res, 24, 147-52.

Adjadj E, Schlumberger M, de Vathaire F (2009). Germ-line DNA polymorphisms and susceptibility to differentiated thyroid cancer. Lancet Oncol, 10, 181-90.

Arnaud J, Bertrais S, Roussel AM, et al (2006). Serum selenium determinants in French adults: the SU.VI.M.AX study. Brit J Nutr, 95, 313-20.

Bleys J, Navas-Acien A, Laclaustra M, et al (2009). Serum selenium and peripheral arterial disease: results from the national health and nutrition examination survey, 2003-2004. Am J Epidemiol, 169, 996-1003.

Brauer VF, Schweizer U, Köhrle J, Paschke R (2006). Selenium and goiter prevalence in borderline iodine sufficiency. Eur $J$ Endocrinol, 155, 807-12.

Brindel P, Doyon F, De Vathaire F, et al (2008). Menstrual and reproductive factors in the risk of differentiated thyroid carcinoma in native women in French Polynesia: a population-based case-control study. Am J Epidemiol, 28, 219-29.

Brindel P, Doyon F, De Vathaire F, et al (2009). Anthropometric factors in differentiated thyroid cancer in French Polynesia: a case-control study. Cancer Causes Control, 20, 581-90.

Brindel P, Doyon F, De Vathaire F, et al (2010). Family history of thyroid cancer and the risk of thyroid cancer in French Polynesia. Thyroid, 20, 393-400.

Cann SA, van Netten JP, van Netten C (2000). Hypothesis: iodine, selenium and the development of breast cancer. Cancer Causes Control, 11, 121-7.

Clark LC, Combs GF, Turnbull BW, et al (1996). Effects of selenium supplementation for cancer prevention in patients with carcinoma of the skin. A randomized controlled trial. Nutritional prevention of cancer study group. JAMA, 276, 1957-63.

Clero E, Doyon F, De Vathaire F, et al (2012). Dietary iodine and thyroid cancer risk in French Polynesia: a case-control study. Thyroid, 22, 422-9.

Clero E, Leux C, De Vathaire F, et al (2010). Pooled analysis of two case-control studies in New Caledonia and French Polynesia of body mass index and differentiated thyroid cancer: the importance of body surface area. Thyroid, 20, 1285-93.

De Vathaire F, Drozdovitch V, Brindel P, et al (2010). Thyroid cancer following nuclear tests in French Polynesia. Brit $J$ Cancer, 103, 1115-21.

Dewailly E, Château-Degat L, Suhas E (2008). Fish consumption and health in French Polynesia. Asia Pac J Clin Nutr, 17, 86-93.

Dewailly E, Suhas E, Mou Y, et al (2008). High fish consumption in French Polynesia and prenatal exposure to metals and nutrients. Asia Pac J Clin Nutr, 17, 461-70.

Dignan C, Burlingame B, Kumar S, Aalbersberg W (2004). The
Pacific Islands food composition tables - second edition. Rome: FAO.

Duffield-Lillico AJ, Reid ME, Turnbull BW, et al (2002). Baseline characteristics and the effect of selenium supplementation on cancer incidence in a randomized clinical trial: a summary report of the nutritional prevention of cancer trial. Cancer Epidemiol Biomarkers Prev, 11, 630-9.

Elwaer N, Hintelmann H (2007). Comparative performance study of different sample introduction techniques for rapid and precise selenium isotope ratio determination using multicollector inductively coupled plasma mass spectrometry (MC-ICP/MS). Anal Bioanal Chem, 389, 1889-99.

Fairweather-Tait SJ, Bao Y, Broadley MR, et al (2011). Selenium in human health and disease. Antioxid Redox Signal, 14, 1337-83.

Favier JC, Ireland-Ripert J, Toque C, Feinberg M (1995). Repertoire general des aliments. Table de composition [Food composition tables] CIQUAL-REGAL. Paris: Tec \& Doc Lavoisier and INRA.

Fleckman P (1985). Anatomy and physiology of the nail. Dermatol Clin, 3, 373-81.

Garland M, Morris JS, Rosner BA, et al (1993). Toenail trace element levels as biomarkers: reproducibility over a 6-year period. Cancer Epidemiol Biomarkers Prev, 2, 493-7.

Glattre E, Thomassen Y, Thoresen SO, et al (1989). Prediagnostic serum selenium in a case-control study of thyroid cancer. Int J Epidemiol, 18, 45-9.

Gudmundsson J, Sulem P, Gudbjartsson D, et al (2009). Common variants on $9 \mathrm{q} 22.33$ and $14 \mathrm{q} 13.3$ predispose to thyroid cancer in European populations. Nat Genet, 41, 460-4.

Guo KF, Zhang Z, Wang JY, et al (2012). Variation of urinary and serum trace elements $(\mathrm{Ca}, \mathrm{Zn}, \mathrm{Cu}, \mathrm{Se})$ in bladder carcinoma in China. Asian Pac J Cancer Prev, 13, 2057-61.

Hunter DJ, Morris JS, Willett WC, et al (1990). Predictors of selenium concentration in human toenails. Am J Epidemiol, 132, 114-22.

Jung HJ, Seo YR (2010). Current issues of selenium in cancer chemoprevention. Biofactors, 36, 153-8.

Karimi G, Shahar S, Homayouni N, et al (2012). Association between trace element and heavy metal levels in hair and nail with prostate cancer. Asian Pac J Cancer Prev, 13, 4249-53.

Kato MA, Finley DJ, Lubitz CC, et al (2010). Selenium decreases thyroid cancer cell growth by increasing expression of GADD153 and GADD34. Nutr Cancer, 62, 66-73.

Köhrle J, Gärtner R (2009). Selenium and thyroid. Best Pract Res Clin Endocrinol Metab, 23, 815-27.

Lloyd B, Lloyd RS, Clayton BE (1983). Effect of smoking, alcohol and other factors on the selenium status of a healthy population. J Epidemiol Community Health, 37, 213-17.

Meinhold CL, Ron E, Schonfeld SJ, et al (2010). Nonradiation risk factors for thyroid cancer in the US radiologic technologists study. Am J Epidemiol, 171, 242-52.

Meplan C, Crosley LK, Nicol F, et al (2007). Genetic polymorphisms in the human selenoprotein $\mathrm{P}$ gene determine the response of selenoprotein markers to selenium supplementation in a gender-specific manner (the SELGEN study). FASEB J, 21, 3063-74.

Moncayo R, Kroiss A, Oberwinkler M, et al (2008). The role of selenium, vitamin $\mathrm{C}$, and zinc in benign thyroid diseases and of selenium in malignant thyroid diseases: low selenium levels are found in subacute and silent thyroiditis and in papillary and follicular carcinoma. BMC Endocr Disord, 8, 2 .

Moore MA, Baumann F, Foliaki S, et al (2010). Cancer epidemiology in the Pacific Islands - past, present and future. Asian Pac J Cancer Prev, 11, 99-106.

Ortega RM, Rodríguez-Rodríguez E, Aparicio A, et al (2012). Young children with excess of weight show an impaired 


\section{Yan Ren et al}

selenium status. Int J Vitam Nutr Res, 82, 121-9.

Ron E, Schneider AB (2006). Thyroid cancer. In: Schottenfeld D, Fraumeni J, editors. Cancer Epidemiology and Prevention. Oxford University Press, New York: pp. 975-94.

Satia JA, King IB, Morris JS, Stratton K, White E (2006). Toenail and plasma levels as biomarkers of selenium exposure. Ann Epidemiol, 16, 53-8.

Singh P, Kapil U, Shukla NK, Deo S, Dwivedi SN (2005). Association between breast cancer and vitamin C, vitamin E and selenium levels: results of a case-control study in India. Asian Pac J Cancer Prev, 6, 177-80.

Willett WC, Polk BF, Morris JS, et al (1983). Prediagnostic serum selenium and risk of cancer. Lancet, 2, 130-4.

World Health Organization (2003). Diet, food supply and obesity in the Pacific. Geneva: regional office for the Western Pacific.

Xhaard C, Ren Y, Clero E, et al (2014). Differentiated thyroid carcinoma risk factors in French Polynesia. Asian Pac J Cancer Prev, 15, 2675-80 